\title{
Do our measurement devices speak the same language?
}

\author{
Michael Radeck \\ Q-DAS GmbH, Customer Service, 69469 Weinheim, Germany
}

\begin{abstract}
Online data recording is becoming more and more important. The current practice results in a large number of different company and plant specific solutions. Measurement device manufacturers have to invest plenty of time and effort for customer specific adaptions of their measurement solution. This article describes the AQDEF data exchange format, a standardized Interface for the management of measurement data, which will reduce this effort.
\end{abstract}

\section{No standardization means effort}

Online data recording and transfer helps to improve process quality and efficiency as well as to increase customer satisfaction. The existing procedure results in a large number of different company and plant specific individual solutions, which have a similar structure, like for example the SPC control of a production process or the acceptance of a facility. For this reason, the measurement device manufacturers have to invest plenty of time and effort for customer specific adaptations, as well as during the specification and control phase at the customers and with regard to investment cost for implementation or license fees.

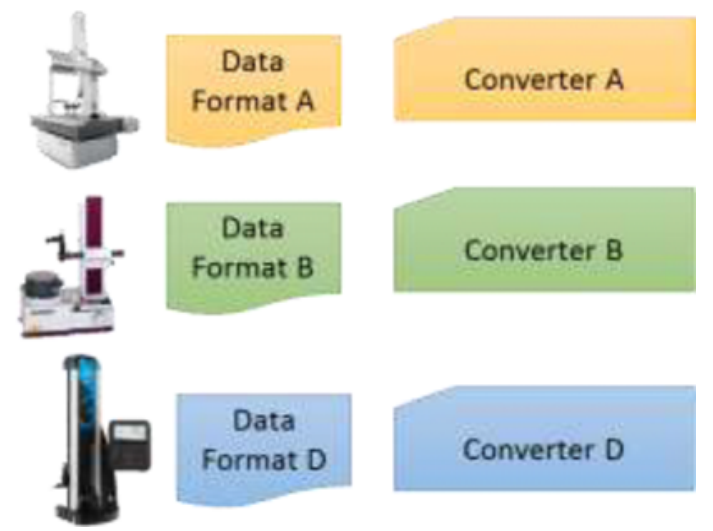

Fig. 1. Typical situation regarding the data format and the Interface of measurement devices for the quality data management in the production area.

\section{Advantages of a standardized data format}

The advantages of a companywide uniform data format are clear. We can combine easily and smoothly the data from different measurement systems. A uniform data format facilitates standardized data storage and the evaluation of measured values. This is a requirement to be able to compare results company-wide. No data conversion is required.
With the objective to find a satisfactory solution for all parties involved, a number of users of the software function "Data Interface" from the automotive production and supplier industry joined forces to create a standardized and coordinated specification
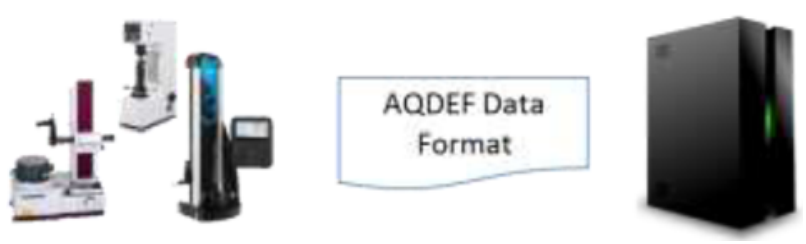

Fig. 2. The standardized data exchange format AQDEF reduces the effort for creating Interfaces and related tasks.

\section{What is the AQDEF data exchange format?}

The AQDEF Work group develops and maintains the Advanced Quality Data Exchange Format (short: AQDEF), a standardized catalogue of data fields important to every user. The objective is to define the scope and interpretation of the key fields and their application.

\section{The AQDEF File Structure}

The data structure is defined in the specification "Advanced Quality Data Exchange Format".

The main features of this data format are:

- A simple, transparent ASCII-based structure

- Flexible (required and optional data fields)

- Space saving

- Easily transferred

- Language independent

In its core, an AQDEF-File is a list of key-value-pairs. Each key starts with the letter $\mathrm{K}$ followed by a four digit numeric value. Its values range groups the key fields according to the following group structure.

*Author: Michael.radeck@q-das.de

(C) The Authors, published by EDP Sciences. This is an open access article distributed under the terms of the Creative Commons Attribution License 4.0 (http://creativecommons.org/licenses/by/4.0/). 


\section{AQDEF-File - Structure Overview}

Table 1. The structure of the content of an AQDEF-File

\begin{tabular}{|c|c|}
\hline \multirow{2}{*}{\multicolumn{2}{|c|}{$\begin{array}{l}\text { Header } \\
\text { Data Block of the first Part }\end{array}$}} \\
\hline & \\
\hline & Part Data of the first part \\
\hline & Characteristic data of the first part \\
\hline \multicolumn{2}{|l|}{$\vdots$} \\
\hline & $\vdots$ \\
\hline & $\vdots$ \\
\hline \multicolumn{2}{|c|}{ Data Block of the $\mathrm{n}^{\text {th }}$ part } \\
\hline & Part data of the $\mathrm{n}^{\text {th }}$ part \\
\hline & Characteristic Data of $\mathrm{n}^{\text {th }}$ part \\
\hline
\end{tabular}

\section{Header Block}

The first line is the header line and contains only one KeyField: K0100. The content of this K-Field is an integer value, which sets the overall number of characteristics given in the file.

\section{Part- and Characteristic-Data Block}

Part data and part related characteristic data are written block-wise (see Table 1). The field- range from K1000 to K1999 is reserved for part related data. The AQDEFspecification has currently defined $38 \mathrm{~K}$-fields for the Part.

The field-range from K2000 to K2999 is reserved for characteristics data. The AQDEF-specification currently uses 64 characteristic related K-Fields.

Table 3 shows a small example of an AQDEF-file - one part, one characteristic and five measurements. This example demonstrates the block structure of the file. The headline has a yellow background color. All cells with a light gray background color belong to the block 'part and characteristic'. The last block is for the measurement data and has no background color.

Table 3. The example shows the typical data-structure of an AQDEF-File

\begin{tabular}{|l|l|}
\hline \multicolumn{1}{|c|}{ K-Field } & \multicolumn{1}{c|}{ Description } \\
\hline K0100 1 & Header (= Number of Characteristics) \\
\hline K1001 EP-1 & Part Number \\
\hline K1002 Part \# 1 & Part Name \\
\hline K1004 AD-001 & Amendment-Status of the Part \\
\hline K1900 Description & Remark for the Part \\
\hline K2001/1 Chr-01 & Number of the first Characteristic \\
\hline K2002/1 Hole M1 & Name of the first Characteristic \\
\hline K2004/1 0 & Data Type \\
\hline K2005/1 3 & Characteristic Class \\
\hline K2006/1 0 & Control Item flag \\
\hline K2009/1 202 & Measured Quantity \\
\hline K2022/1 3 & Number of decimal places \\
\hline K2101/1 30.000 & Nominal Value of the first Character. \\
\hline K2110/1 29.970 & Lower Limit of the $1^{\text {st }}$ Characteristic \\
\hline K2111/1 30.03 & Upper Limit of the $1^{\text {st }}$ Characteristic \\
\hline
\end{tabular}

\begin{tabular}{|l|l|}
\hline K2112/1 -0.03 & Lower Allowance of the $1^{\text {st }}$ Charac. \\
\hline K2113/1 0.03 & Upper Allowance of the $1^{\text {st }}$ Charac. \\
\hline K2120/1 1 & Lower Boundary Type \\
\hline K2121/1 1 & Upper Boundary Type \\
\hline K2142/1 mm & Unit of the first Characteristic \\
\hline K2404/1 0.001 & Gage Resolution \\
\hline K2900/1 Description & Description of the $1^{\text {st }}$ Characteristic \\
\hline K0001/1/1 30.001 & $1^{\text {st }}$ Measurement of the $1^{\text {st }}$ Character. \\
\hline K0002/1/1 0 & Attribute of the $1^{\text {st }}$ Measurement \\
\hline K0001/1/2 30.008 & $2^{\text {nd }}$ Measurement of the $1^{\text {st }}$ Character. \\
\hline K0002/1/2 0 & Attribute of the $2^{\text {nd }}$ Measurement \\
\hline K0001/1/3 30.002 & $3^{\text {rd }}$ Measurement of the $1^{\text {st }}$ Character. \\
\hline K0002/1/3 0 & Attribute of the $3^{\text {rd }}$ Measurement \\
\hline K0001/1/4 30.003 & $4^{\text {th }}$ Measurement of the $1^{\text {st }}$ Character. \\
\hline K0002/1/4 0 & Attribute of the $4^{\text {th }}$ Measurement \\
\hline K0001/1/5 29.994 & $5^{\text {th }}$ Measurement of the $1^{\text {st }}$ Character. \\
\hline K0002/1/5 0 & Attribute of the 5 th Measurement \\
\hline
\end{tabular}

\section{AQDEF Certification Categories}

One focus of the AQDEF work group is the definition of requirements of multiple specifications for interfaces and data formats. The intended application dictates the range of supported Key-Fields. The AQDEF work group has defined five categories of use cases:

Table 2. Certification categories based on use cases for the AQDEF-Data Interface

\begin{tabular}{|l|l|l|}
\hline Category & \multicolumn{1}{|c|}{ Description } & \multicolumn{1}{c|}{ Remark } \\
\hline A & $\begin{array}{l}\text { Variable and attribute } \\
\text { characteristics including } \\
\text { positional deviations }\end{array}$ & $\begin{array}{l}\text { Full certification } \\
\text { scope }\end{array}$ \\
\hline B & $\begin{array}{l}\text { Variable characteristics } \\
\text { including positional } \\
\text { deviations }\end{array}$ & \\
\hline C & $\begin{array}{l}\text { Variable characteristics } \\
\text { (without positional } \\
\text { deviations) }\end{array}$ & \\
\hline D & $\begin{array}{l}\text { Discrete characteristics } \\
\text { (no variable } \\
\text { characteristics) }\end{array}$ & \\
\hline E & Header Data & \\
\hline
\end{tabular}

The choice of a specific use case category becomes handy when customer and supplier have to specify the data interface for a new measurement solution.

\section{Conclusion}

A key task in all production companies is the management of measurement data and related information. The AQDEF data exchange format provides a common language that makes it easy to handle the structure and content of measurement data. The user specification of the AQDEF work group offers recommendations for the development of an AQDEF interface.

\section{Reference}

1. AQDEF working group: AQDEF-Specification 